\title{
METODE
}

\section{PRIMERJALNA ANALIZA MODELOV POKROVNOSTI IN RABE ZEMLJIŠČ V IZBRANIH DRŽAVAH}

\author{
AVTORICE \\ dr. Mojca Foški \\ Univerza v Ljubljani, Fakulteta za gradbeništvo in geodezijo, Jamova cesta 2, SI - 1000 Ljubljana, Slovenija \\ mfoski@fgg.uni-lj.si
}

\author{
Nataša Đurić \\ Center odličnosti Vesolje-SI, Aškerčeva cesta 12, SI - 1000 Ljubljana, Slovenija \\ natasa.dzuric@space.si
}

\section{Katja Tič}

Geodetski inštitut Slovenije, Jamova cesta 2, SI - 1000 Ljubljana, Slovenija

katja.tic@gis.si

\section{dr. Mihaela Triglav Čekada}

Geodetski inštitut Slovenije, Jamova cesta 2, SI - 1000 Ljubljana, Slovenija

mihaela.triglav@gis.si

DOI: $10.3986 / G V 90106$

UDK: 711.14(4)

COBISS: 1.02

\section{IZVLEČEK}

\section{Primerjalna analiza modelov pokrovnosti in rabe zemljišč v izbranih državah}

$V$ prispevku so predstavljeni modeli pokrovnosti in rabe zemljǐ̌č $v$ Avstriji, Nemčiji, na Nizozemskem in $v$ Veliki Britaniji ter aktivnosti v okviru evropskih projektov EAGLE, HELM in LUCAS. Posamezne države so modele pokrovnosti in rabe zemljišč vzpostavile glede na svoje potrebe ter jih različno uskladile z mednarodnimi prostorskimi podatki. Za vzpostavitev državne baze podatkov o pokrovnosti in rabi zemljišč lahko uporabimo tudi podatke o rabi kmetijskih in gozdnih zemljišč, vzpostavljene za namen izvajanja evropske kmetijske politike. VSloveniji se podatki o pokrovnosti, ki jih je vzpostavil Statistični urad Republike Slovenije, ne vzdržujejo več. Podatki kmetijskega ministrstva, ki se vzdržujejo, pa ne pokrivajo z enako podrobnostjo vseh rab. V prispevku predstavljena primerjalna analiza modelov nam lahko služi kot razmislek ter izhodišč $k$ vzpostavitvi modela pokrovnosti in rabe zemlijišč tudi v Sloveniji.

\section{KLJUČNE BESEDE}

pokrovnost, raba tal, primerjalna analiza, Slovenija 


\begin{abstract}
Comparative analysis of land cover and land use models in selected countries

This paper presents land cover and land use models in Austria, Germany, The Netherlands, and Great Britain and the activities under the European projects EAGLE, HELM and LUCAS. These models have been set up for, and depending on, national requirements and also depending on international spatial data harmonisation. The data on land use of agricultural and forest land, set up for the purpose of implementing the Common (European) Agricultural Policy, are also applicable for setting up the national database on land cover and land use. In Slovenia, the land cover data set up by the Statistical Office of the Republic of Slovenia are no longer updated, while the data by the ministry responsible for agriculture do not cover all land uses with the same level of detail. The comparative analysis of the models can serve as a reflection and starting point for the establishment of a land cover and land use model in Slovenia as well.
\end{abstract}

\title{
KEY WORDS
}

land cover, land use, comparative analysis, Slovenia

Uredništvo je prispevek prejelo 5. februarja 2018. 


\section{Uvod}

Spremljanje spreminjanja dejanske rabe zemljišč (v nadaljevanju raba) in pokrovnosti je temelj za razumevanje družbenih procesov ter učinkovito upravljanje s prostorom (Anderson in sodelavci 1976). Pomembno je, da pomensko razlikujemo med rabo in pokrovnostjo, saj je za določitev ene ali druge kategorije pomembna metodologija dela ter nabor potrebnih baz podatkov. Razlike med obema kategorijama se večajo $\mathrm{z}$ manjšanjem merila opazovanja in podrobnostjo členitve prostora (Kokalj in Oštir 2005).

Opredelitve pokrovnosti (angl. land cover) se med viri (INSPIRE 2013a; 2014; EEA 2015; FAO 2017) ne razlikujejo bistveno in pokrovnost opredeljujejo kot biološki in fizični pokrov zemeljskega površja. Pokrovnost je konkretna in jo lahko v prostoru neposredno opazujemo v nasprotju $\mathrm{z}$ rabo, ki je abstraktna razsežnost prostora in je včasih ne moremo določiti niti s podrobnim terenskim ogledom (Campbell 1996 v: Kokalj in Oštir 2005).

Raba zemljišč (land use) je po definiciji (INSPIRE 2013b; FAO 2017; SURS 2017) opredeljena kot dejavnost, oziroma koriščenje zemeljskega površja z namenom proizvodnje, uporabe, vzdrževanja in je torej socioekonomska razsežnost prostora. Razlikujemo med dejansko rabo, ki opredeljuje trenutno dejavnost oziroma koriščenje prostora (Metodologija ... 2018) in namensko rabo, ki opredeljuje predvideno dejavnost oziroma koriščenje prostora in je določena v prostorskih dokumentih (Zakon ... 2017).

Povezavo med pokrovnostjo in rabo direktiva INSPIRE (2013a; 2013b) opisuje kot vzajemni odnos. Spremembe rabe se pogosto zaznavajo z opazovanjem sprememb pokrovnosti, saj sta pokrovnost in raba velikokrat soodvisni (Arnold in sodelavci 2014; Antrop 2005; Ellis 2010; Tavares, Pato in Magalhaes 2012), kar še posebej velja zunaj poseljenega prostora. Pokrovnost praviloma najlažje in najpogosteje zaznavamo s tehnikami daljinskega zaznavanja, medtem ko je za določanje rabe potreben bistveno večji nabor razpoložljivih podatkov in pazljivost pri interpretaciji prostora (namen uporabe prostora).

Tako kot Comber (2008), Ben-Asher (2013) ter Manakos in Braun (2014) smo tudi mi pri pregledu literature opazili, da se pri opisovanju Zemljinega površja, ne glede na to, ali gre vsebinsko za biološke in fizične elemente ali za socioekonomske funkcije, uporabljata oba izraza ter, da pogosto med njima ni jasne ločnice. V anglosaksonski literaturi najpogosteje srečamo kar kratico (LC/LU) (Land Cover/Land Use), s čimer se avtorji izognejo razmejevanju, bodisi ker za to ni potrebe ali ker to ni smiselno. Podobno združevanje rabe in pokrovnosti uporablja tudi Komisija za spremembe rabe in pokrovnosti tal pri Mednarodni geografski zvezi (Medmrežje 1), kjer spremembe rabe/pokrovnosti opredelijo kot LUCC (Land Use Cover Change).

Tudi pri pregledu slovenske literature so nedoslednosti. Že poimenovanje Evidence dejanske rabe kmetijskih in drugih zemljišč (v nadaljevanju EDRKDZ) (Pravilnik 2008; 2010) Ministrstva za kmetijstvo, gozdarstvo in prehrano je, glede na to, da se biološki pokrov površja določa z vizualno interpretacijo ortofoto posnetkov (DOF), neustrezno. Izraza »raba prostora «ali »raba zemljišč« se pogosto uporabljata tudi v primerih, ko dejansko odsevata pokrovnost.

$\mathrm{V}$ zadnjih dveh desetletjih je spremljanje sprememb pokrovnosti in rabe postalo pomembno za različna strokovna področja (Manakos in Braun 2014). Navkljub pomembnosti podatkov o pokrovnosti in rabi Ben-Ascher (2013) ugotavlja, da se podatki v Evropi zbirajo neučinkovito, spremljanje stanja in sprememb ni natančno regulirano, zbrani podatki pa se med državami razlikujejo tako po metodah zajema kot po interpretaciji zajetih podatkov.

Edini sistemski vir rabe oziroma pokrovnosti, ki se redno vzdržuje v Sloveniji, je EDRKDZ, ki pa ima zaradi temeljnega namena vzpostavitve za potrebe dodeljevanja kmetijskih subvencij, omejeno uporabo za druge namene, na kar so opozorili Krevs (2004), Lisec, Pišek in Drobne (2013) ter Foški (2018). Statistična GIS pokrovnost in raba zemljišč Statističnega urada Republike Slovenije se od leta 2005 ne izdeluje več (Skumavec in Šabić 2005; SURS 2007). Podatki pokrovnosti iz podatkovne baze CORINE Land Cover (CLC) Evropske agencije za okolje (EEA) so dostopni za leta 1995, 2000, 2006 in 2012 ter so primerni zgolj za grobe primerjalne analize na ravni Evrope, saj je najmanjša enota kartiranja (MMU minimum mapping unit) 25 ha. Na ravni poseljenega območja so primernejši podatki Urban Atlas (UA) 
Evropske agencije za okolje z najmanjšo enoto kartiranja 0,25 ha, ki prikazujejo zaznane spremembe rabe v obdobju 2006-2012. Osnova so podatki CLC, podrobnejši prikaz za poseljena območja pa je rezultat uporabe dodatnih podatkovnih baz (Copernicus ... 2107). Za Slovenijo so dostopni podatki za osrednjeslovensko in podravsko statistično regijo (Medmrežje 2). Na ravni posamezne države/regije/lokalne skupnosti so to praviloma prevelike enote kartiranja in ne pokažejo manjših, a pomembnih sprememb v prostoru (na primer zaraščanje kmetijskih zemljišč, izgradnja posameznega objekta) ter pomembnih razlik med regijami in lokalnimi skupnostmi znotraj države. Zaradi prevelike enote kartiranja ter omejenosti podatkov le na nekatera območja države (na primer v UA), teh podatkov ne moremo uporabiti za sprotno spremljanje sprememb, zaradi česar bi lahko in tudi morali evidenci pokrovnosti/rabe vzpostaviti in vzdrževati.

Evidence pokrovnosti/rabe na območju kmetijskih zemljišč so vzpostavile vse države, podrejene skupni evropski kmetijski politiki. Stanje glede zagotavljanja drugih sistemskih rešitev pokrovnosti/rabe, ki bi z enako skrbnostjo zagotovile podatke za vse skupine pokrovnosti/rabe (ne zgolj kmetijske), se med evropskimi državami razlikuje. $Z$ namenom iskanja odgovorov, kako vzpostavitvi evidenco pokrovnosti/rabe in spremljanje stanja prostora v Sloveniji, smo naredili pregled modelov in pristopov v nekaterih izbranih evropskih državah ter aktivnosti v okviru izvedenih mednarodnih projektov. Z ovrednotenjem njihovih modelov in izkušenj bi lahko oblikovali izhodišča za vzpostavitev državne evidence pokrovnosti in rabe $\mathrm{v}$ Sloveniji.

\section{Metodologija dela}

V primerjalno analizo modelov pokrovnosti/rabe, opravljeno na podlagi literature in dostopnih virov, smo uvrstili evropske države Avstrijo, Nizozemsko, Nemčijo in Veliko Britanijo. Nizozemska, Nemčija in Velika Britanija imajo že dlje časa vzpostavljen sistem evidence rabe/pokrovnosti in posledično več iteracij podatkov. Na podlagi sprememb, ki so jih izvedli ob vsaki novi različici podatkovne baze, se lahko veliko naučimo. V Avstriji so začeli raziskovalni projekt, saj evidenca na ravni države še ni vzpostavljena. Namen vzpostavitve, razvita metodologija in faze projekta so lahko zanimive tudi za Slovenijo.

Pregledali smo nekatere mednarodne projekte: EAGLE (European Action Group for Land Monitoring in Europe), HELM (Harmonised European Land Monitoring) in aktivnosti znotraj projekta LUCAS (Land Use and Cover Area Frame Survey), ki so bili za namen harmonizacije podatkov na ravni EU izvedeni v zadnjem desetletju.

Pri analizi smo bili pozorni predvsem na:

- uporabo klasifikacijskega modela,

- pristop glede razmejevanja med rabo in pokrovnostjo,

- število razredov pokrovnosti/rabe,

- tehnične značilnosti (viri podatkov, minimalna enota zajema, vzdrževanje).

Stanje, izkušnje in trende smo na kratko povzeli, podatke pa prikazali tabelarično.

\subsection{Klasifikacijski modeli}

Temeljni vir metodologije oblikovanja klasifikacijskih modelov na področju pokrovnosti/rabe je Priročnik za oblikovanje konceptov za pokrovnost in dejansko rabo zemljišč (Manual ... 2001), ki ga je objavilo Združenje občin pri Evropski komisiji. Priročnik klasifikacijske modele opredeljuje kot orodja, ki opisujejo izbrane značilnosti stanja v naravi, in jih deli v hierarhične in nehierarhične modele. V hierarhičnem modelu (najpogosteje drevesna struktura) so objekti razvrščeni v skupine tako, da je med objekti skupine čim večja podobnost, med skupinami pa čim večja različnost (Manual ... 2001). $\mathrm{V}$ hierarhične modele razvrščamo praviloma razrede rabe in pokrovnosti (primer preglednica 1). 
Med nehierarhičnimi modeli se najbolj uveljavljajo objektni modeli, kjer pripišemo vsakemu objektu čim več značilk. Značilka ali atribut podaja lastnosti objekta. Na podlagi pomenske (semantične) matrike izvedemo razvrščanje objektov, ki pa se lahko spreminja $\mathrm{v}$ odvisnosti od namena in potrebe uporabnika. Načela oblikovanja so podrobneje opisana v omenjenem priročniku (Manual ... 2001).

\subsection{Odnos med rabo in pokrovnostjo}

Raba in pokrovnost sta praviloma soodvisni. Raba običajno vključuje pokrovnost, nasprotno pa to ne velja (Plieninger in sodelavci 2016). Odnosi med kategorijo pokrovnosti in rabo (slika 1) so lahko v razmerju 1:1 (na primer pokrovnost njiva - vedno kmetijska raba), v odnosu 1:n (slika 2) ali n:1 (pokrovnost makadam, travinja in objekt - skupaj industrijska raba). Zaradi kombinacije $1: \mathrm{n}$ in $\mathrm{n}: 1$ (sliki 1 in 2) podatke pokrovnosti ne moremo enoznačno pretvoriti v rabo, posledično se razlikuje tudi število kategorij rab in pokrovnosti, kar je razvidno iz analize Okršlarja (2015).

Zelo pogosto se težave določanja rabe pokažejo pri gozdu (slika 2), saj zaradi drevesnih krošenj ne moremo določiti rabe pod njimi (na primer zakrijejo prometnico, objekt, rekreacijske naprave). Enaka težava nastane pri interpretaciji travinje (pokrovnost), ko ne moremo jasno določiti ali je to kmetijska

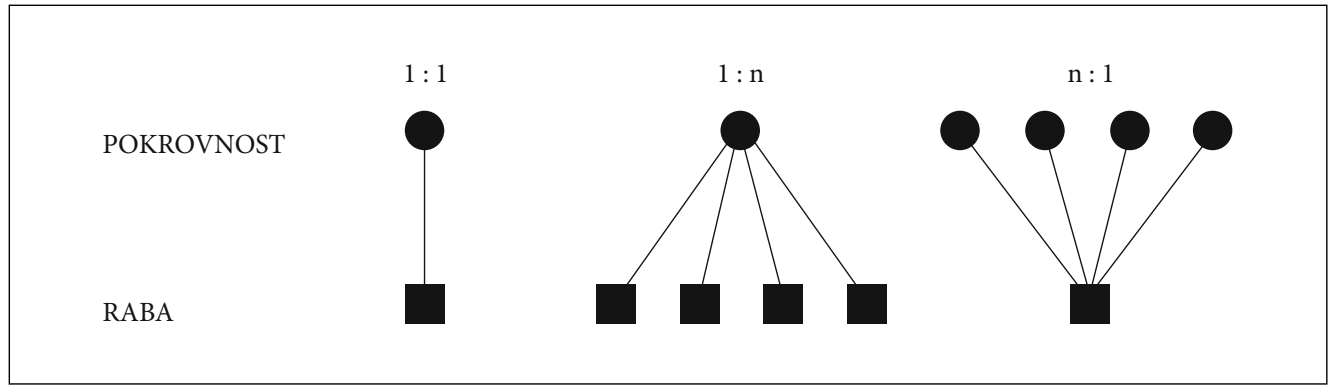

Slika 1: Možna razmerja med kategorijami pokrovnosti in rabe.

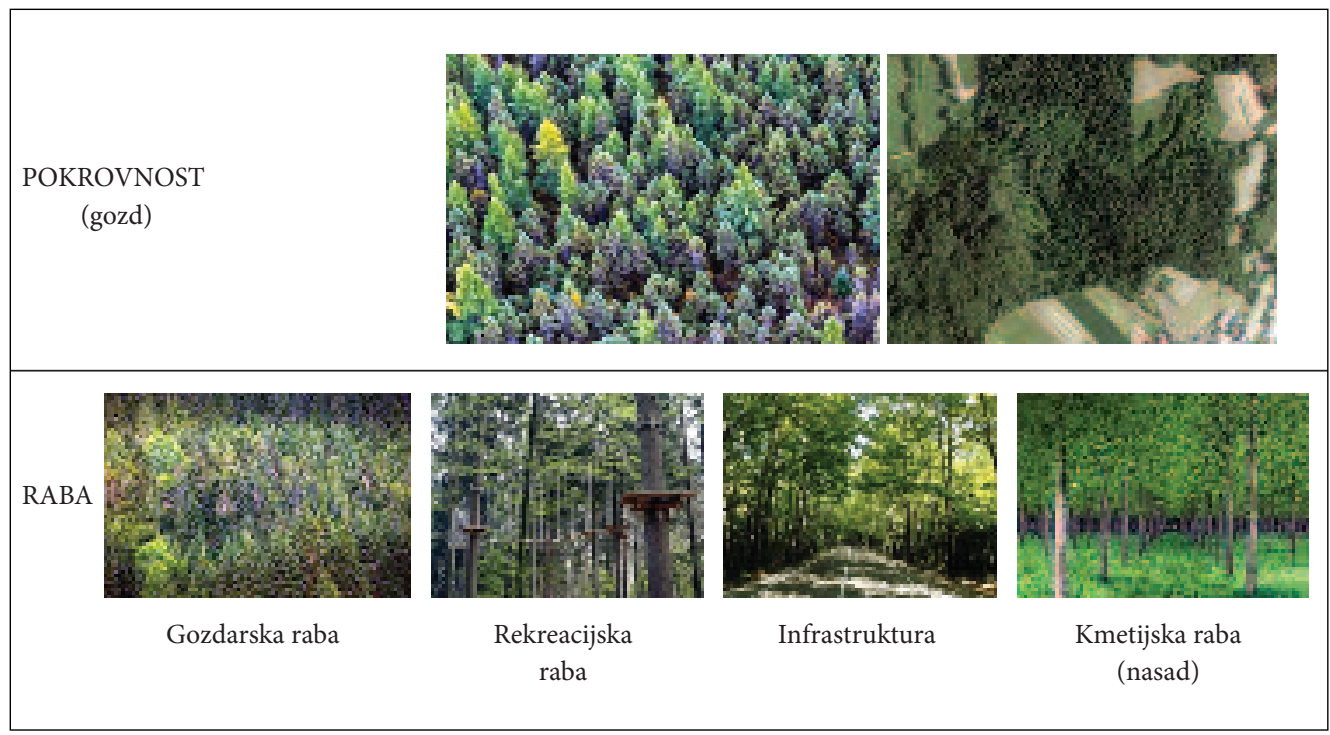

Slika 2: Razmerje 1:n (slika 1) na primeru gozda. 
raba (travnik, pašnik), rekreacijska raba (na primer travnato nogometno igrišče) ali infrastruktura (na primer travnata letališka steza). Za določanje rabe potrebujemo še vrsto drugih podatkov (na primer register dejavnosti, pravni akti), včasih pa je potreben tudi terenski ogled. Rabe so lahko izključne ali sočasne (Pogačnik 1992). Predvsem sočasne rabe je težko določiti zgolj na podlagi pokrovnosti. Tak primer je pogosto rekreacijska raba ( $v$ naravnem okolju), ki se prepleta s kmetijsko ali gozdarsko rabo.

Iz pokrovnosti lahko le sklepamo o rabi, ničesar pa ne vemo o intenzivnosti izrabe tega območja. Če se bo intenzivnost izrabe določene rabe spremenila, to ne bo vplivalo na pokrovnost. Tudi če se bo spremenila dejavnost (na primer iz stanovanjske v poslovno) se to ne bo odrazilo na pokrovnosti. Šele velike spremembe intenzitet rabe se odrazijo tudi v spremembi pokrovnosti (Van der Sluis in sodelavci 2015). Zaradi navedenih dejstev moramo razlikovati med rabo in pokrovnostjo ter razumeti, da šele ločena podatkovna sloja izboljšata informacije o prostoru.

\section{Primerjalna analiza modelov pokrovnosti in rabe $v$ izbranih državah}

\subsection{Avstrija}

Avstrija je leta 2009 začela s pilotnim projektom LISA (Land Information System Austria), katerega namen je vzpostaviti učinkovit sistem spremljanja stanja ter predvsem sprememb pokrovnosti in rabe. Oblikovan je bil konzorcij vladnih, gospodarskih in raziskovalnih institucij (Medmrežje 3). V projektu so se pretežno opirali na podatke, pridobljene s tehnikami daljinskega zaznavanja. Uporabili so podatke ortofota s prostorsko ločljivostjo $20 \mathrm{~cm}$, laserskega skeniranja, podatke Copernicus, satelitske posnetke Pléiades s prostorsko ločljivostjo $2 \mathrm{~m}$ ter tudi vse razpoložljive državne prostorske baze (National Spatial Data Infrastructure) (Banko in sodelavci 2014; Manakos in Braun 2014).

Za vzpostavitev so uporabili objektni model, kjer sta raba in pokrovnost ločeni. Pokrovnost vsebuje 13 razredov, razvrstitev v razrede pa se izvede izključno iz podatkov daljinskega zaznavanja (ortofoto, višinski podatki, satelitski posnetki in lasersko skeniranje) ter postopkov samodejne segmentacije in klasifikacije v merilu 1:10.000. Najmanjša enota kartiranja (MMU) je $25 \mathrm{~m}^{2}$ za objekte, druga grajena območja (na primer ceste, parkirišča) in drevesa (posamezna drevesa ali drevesa v gruči) ter $50 \mathrm{~m}^{2}$ za ostale kategorije (preglednica 1).

Kartiranje pokrovnosti se izvede z metodo segmentacije - segmenti so določeni glede na spektralne, radiometrične in teksturne parametre. $Z$ uporabo nizov pravil se izvede klasifikacija posameznega razreda. Testno kartiranje pokrovnosti so v prvi fazi opravili na štirih testnih območjih v velikosti $1600 \mathrm{~km}^{2}$ ter nato še za dodatnih $10.000 \mathrm{~km}^{2}$, ki pokrivajo največja poselitvena območja v Avstriji. Validacijo podatkov so opravili na znanstvenih institucijah (Austrian Institute of Technology, BOKU - Universität für Bodenkultur Wien in TUW - Technische Universität Wien), ki so potrdili visoko kakovost podatkov (CadasterENV 2017).

Iz razredov pokrovnosti so s pomočjo preseka z ostalimi prostorskimi podatki, kot so zemljiški kataster, namenska raba, podatki o prometni infrastrukturi ter podatki ministrstva za kmetijstvo in gozdarstvo, prešli v šest osnovnih kategorij rabe: pozidana zemljišča, promet, kmetijstvo, gozdarstvo, odprt prostor (z rastjem, brez rastja), vode. Nato pa še v podrobne kategorije rabe s 26 razredi in 72 značilkami. Objektni model omogoča združevanje kategorij rabe v odvisnosti od namena uporabe. Kartiranje rabe na 17 testnih območjih je bilo izvedeno v merilu $1: 25.000 \mathrm{z}$ najmanjšo enoto kartiranja $1000 \mathrm{~m}^{2}$ za območje poselitve in $5000 \mathrm{~m}^{2}$ za ostala območja. Z metodo vzorčenja so na testnih območjih preverjali ustreznost oblike poligona in pripisane rabe. Ocena geometrične pravilnosti kartiranih poligonov je bila $90 \%$, vsebinske pravilnosti pripisane rabe pa $88 \%$, s čimer so bili zadovoljni (Banko in sodelavci 2014).

V obdobju 2012-2015 je potekal projekt harmonizacije s katastrom (CadasterENV Austria). Sočasno s kartiranjem pokrovnosti na podlagi visokoločljivostnih satelitskih posnetkov (Pléiades in WordView-2) 
Preglednica 1: Razredi pokrovnosti LISA (po Banko in sodelavcih 2014).

\begin{tabular}{lllc}
\hline raven 1 & raven 2 & raven 3 & $\begin{array}{c}\text { minimalna enota } \\
\text { kartiranja }\left(\mathrm{m}^{2}\right)\end{array}$ \\
\hline \multirow{2}{*}{ abiotski elementi } & pozidano & stavbe & 25 \\
& & druga pozidana območja & 50 \\
\cline { 2 - 4 } & nepozidano & gola tla & 50 \\
& & melišča & 50 \\
\cline { 2 - 4 } & vode & skalovja & 50 \\
\hline biotski elementi & gozdovi & sneg & 50 \\
& & led & 50 \\
& & drevesa & 50 \\
\cline { 2 - 4 } & zelnate rastline & grmičevja & 50 \\
& ruševje & 50 \\
& & zelnata vegetacija & 50 \\
\hline nerazvrščeno & trstičja & 50 \\
& & sence & 50 \\
\hline
\end{tabular}

so se osredotočili na razvoj metod za kartiranje vročih točk (hotspots), kjer prihaja do večjih ali pogostejših sprememb pokrovnosti. Usmerjenost aktivnosti na območje vročih točk pomeni pri vzdrževanju in spremljanju stanja prihranek denarja in časa (Development ... 2018).

V četrti fazi projekta (obdobje 2015-2017) so s podatki Sentinel-2 prostorske ločljivosti $10 \mathrm{~m}$ (večja prostorska ločljivost) in časovno vrsto 5-10 dni (gostejša časovna vrsta) izboljšali kakovost pokrovnosti ter omogočili hitrejše ugotavljanje sprememb in spremljanje stanje. Pri zaznavanju sprememb so se osredotočili na trajne spremembe (izgradnja novih objektov in cest), sezonske spremembe (na primer $\mathrm{v}$ kmetijstvu) in potekajoče spremembe (na primer zaraščanje) (CadasterENV ... 2018).

Pomemben sestavni del projekta LISA je kartiranje podatkov. Kot ločeni rezultati so zasnovane karte pokrovnosti, karte rabe prostora, avtomatsko izdelane karte sprememb (vročih točk) ter sloj združenih podatkov (pokrovnosti in rabe) za potrebe na evropski ravni (na primer posodobitev CLC) (LISA ... 2017).

\subsection{Nizozemska}

Nizozemska ima bogato zgodovino kartiranja rabe in pokrovnosti. Na državni ravni obstajajo štiri podatkovne baze, ki vključujejo zvezni sloj pokrovnosti/rabe: katastrska topografska baza (Top10vector/Top10NL), karta rabe tal (Bestand BodemGebruik - BBG), CORINE Land Cover (evropska baza), najpomembnejša pa je Državna baza pokrovnosti - Landelijk Grondgebruiksbestand Nederland (LGN).

Danes obstaja sedem različic baze LGN: 1986, 1992/1994, 1995/1997, 1999/2000, 2003/2004, 2007/2008, 2012/2013 (Hazeu in sodelavci 2011; The Land ... 2015; LGN7 2017; What is ...). Zadnji LGN7 je nastal v letih 2012/2013 na podlagi predhodne baze LGN6 (2008), Top10NL (2012), LPIS zemljiški informacijskega sistema (2012), digitalne karte rabe (BBG 2008) in osnovne karte naravnih območij (BKN 2012). Vključene so tudi druge podatkovne baze. Pri izdelavi kart pokrovnosti in rabe so uporabili satelitske posnetke Landsat s prostorsko ločljivostjo $30 \mathrm{~m}$ in posnetke satelita IRS-P6 s prostorsko ločljivostjo 5,8 m (LISS-IV), 23,5 m (LISS-III), $56 \mathrm{~m}$ (AWiFS). Letalske posnetke z ločljivostjo 0,5 m so uporabili predvsem za določanje podrobnih kategorij na območju kmetijskih zemljišč. S pomočjo 
indeksa NDVI so podrobneje razmejili kmetijska zemljišča na polja s travinjem, koruzo, krompirjem, sladkorno peso, pšenico, ostale poljščine in cvetne nasade (Hazau 2014).

Tako kot vse predhodne baze LGN je tudi LGN7 rastrska baza z velikostjo celice $25 \mathrm{~m} \times 25 \mathrm{~m}$. Število razredov pokrovnosti se je od 17 pri LGN-1 ustalilo pri 39 (od LGN-3 naprej), vključujoč pozidana zemljišča, tipe gozdov, vodo, tipe poljščin in številne ekološke razrede.

Metodologija izdelave pokrovnosti/rabe se je od LGN-4 naprej nekoliko spreminjala, vendar omogoča medsebojno primerjavo podatkovnih slojev in ugotavljanje sprememb. Za potrebe ugotavljanja sprememb so iz 39 razredov oblikovali osem razredov (poseljeno, sadovnjaki, rastlinjaki, kmetijska zemljišča, vode, infrastruktura, gozd in narava). Podrobno sta metodologijo ugotavljanja sprememb pokrovnosti opisala De Witt (2003) in Hazeu (2006), ki sta ugotovljene spremembe tudi ovrednotila.

\subsection{Nemčija}

Na podlagi tristranskega dogovora med Državnim uradom za kartografijo in geodezijo (BKG), Državnim uradom za okolje (UPBA) ter Ministrstvom za okolje, naravo in jedrsko varnost (BMU) so v Nemčiji leta 2007 pričeli z dolgoročnim projektom vzpostavitve vektorske baze pokrovnosti in rabe. Pri vzpostavitvi so izhajali iz obstoječih nacionalnih podatkovnih baz, predvsem ATKIS (Das Amtliche Topographisch-Kartographische Informationssystem) ter vektorske podatke kombinirali s podatki, pridobljenimi s pomočjo avtomatske klasifikacije različnih rastrskih virov IMAGE2006, FTS, REFINA, GSE Forest. Projekt se imenuje DLM (Digitales Landbedeckunsgmodell für Deutchland) ali kar DLMDE (Hovenbitzer in sodelavci 2014).

Prva obnova je potekala leta 2009. Kot vir za izboljšavo so bili uporabljeni poligoni poselitve, prometa, vegetacije in vode iz obstoječe baze DLM-DE 2006, podatki pa dopolnjeni s podatki, pridobljenimi $\mathrm{z}$ avtomatsko klasifikacijo daljinskih posnetkov. Kot osnovni vir so uporabili veččasovne posnetke RapidEye z ločljivostjo $5 \mathrm{~m}$, kot dopolnilni vir pa posnetke DMC (Disaster Monitoring Constellation) z ločljivostjo $32 \mathrm{~m}$. Uporabljali so tudi druge vire daljinskega zaznavanja (IMAGE2006, državni ortofoto, izdelke Copernicus). Najmanjša enota kartiranja je bila 1 ha za vsa območja in vse kategorije pokrovnosti. Določili so 37 razredov pokrovnosti, pri čemer so bili uporabljeni enaki razredi pokrovnosti kot pri CLC (CORINE Land Cover), ki ima 44 razredov pokrovnosti. Rezultat iz leta 2009 je prvi zvezni vektorski sloj pokrovnosti za Nemčijo (Hovenbitzer in sodelavci 2014; Keil in sodelavci 2015).

Na podlagi preseka med DLM-DE 2006 in DLM-DE 2009 so izluščili 46 različnih kombinacij sprememb, ki so jih nato združili $\mathrm{v}$ devet razredov (povečanje intenzivnosti $\mathrm{v}$ kmetijstvu, zmanjšanje intenzivnosti v kmetijstvu, zaraščanje, izguba gozda, urbanizacija, območja pridobivanja rudnin, rekultivacija, nova vodna območja, drugo) (Keil in sodelavci 2015).

Zaradi usklajevanja s CLC 2012 so leta 2012 obnovili bazo DLM-DE, pri čemer so izkoristili tudi dostopnost satelitskih posnetkov Evropske vesoljske agencije (ESA). Uvedli so nekatere metodološke spremembe, za obnovo pa uporabili satelitske posnetke RapidEye 2011, RapidEye 2012, DMC (Disaster Monitoring Constellation), IMAGE2012, SPOT, IRS, ortofoto posnetke. Najmanjša enota kartiranje je ostala 1 ha. Vzpostavljen je bil nov klasifikacijski sistem, na podlagi katerega so lahko vzpostavili povezavo med nacionalno bazo podatkov in kategorijami CLC (Digitales ... 2012). Hkrati sta se vzpostavili ločeni bazi pokrovnosti in rabe, ki ponujata popolnejše podatke o vsakem poligonu ter možnost pomenskega povezovanja $\mathrm{z}$ drugimi bazami. Ločenost baz je olajšala obnovo in interpretacijo podatkov. Pokrovnost določajo z metodami daljinskega zaznavanja, praviloma $\mathrm{z}$ objektno usmerjeno analizo, medtem ko je bila raba že določena v nacionalnih bazah ATKIS. Hovenbitzer in sodelavci (2014) ugotavljajo, da večini kategorij pokrovnosti ne moremo enoznačno pripisati iste rabe. V prihodnosti predvidevajo izboljšavo pokrovnosti predvsem na območju kmetijskih zemljišč (ločnice med obdelovalnimi zemljišči in travinjem) z uporabo visokoločljivih satelitskih posnetkov Sentinel-1 in Sentinel-2 (Keil in sodelavci 2015). 


\subsection{Velika Britanija}

Prva karta pokrovnosti v Veliki Britaniji je nastala leta 1990 (Land Cover Map of GreatBritain LCMGB) izključno iz podatkov daljinskega zaznavanja (polavtomatska klasifikacija spektralnih podatkov, pridobljenih iz posnetkov Landsat). Določenih je bilo 25 razredov pokrovnosti, osnovna enota je bila celica velikosti $25 \mathrm{~m} \times 25 \mathrm{~m}$. Bolj kot v uporabnost končnega izdelka (karte) so se usmerili v uporabo samodejnih postopkov obdelave satelitskih posnetkov. Razvoj od LCM2000 do LCM2007 je potekal v okviru projekta CLEVER-Mapping (The Classification of Environment with Vector-and Raster-Mapping), kjer so razvili objektno orientirani pristop, uporabili kombinacijo različnih rastrskih podatkov ter drugih numeričnih in vektorskih podatkovnih baz. Spremenili so klasifikacijo razredov (23 razredov, skladno z nomenklaturo Joint Nature Conservation Committee), najmanjša enota kartiranja je bila 0,5 ha. Metodologija dela je podrobno opisana v Smith (2014). LCM2007 (Land Cover Map ... 2011) je bila izboljšana s samodejno klasifikacijo posnetkov Landsat, SPOT in IRC in uporabo drugih podatkov. Različica LCM2007 je parcelno naravnana, objektno orientirana, dostopni so rastrski in vektorski podatki v različnih podatkovnih slojih ter prostorski ločljivosti (raster velikosti slikovnega elementa $25 \mathrm{~m}^{2}$ ali $1 \mathrm{~km}^{2}$ ). Vsak poligon ima pripisanih 10 značilk (Land Cover Map ... 2016).

Zadnja različica LCM2015 temelji na podatkih Landsat 8 (ločljivost $30 \mathrm{~m}$ ), posnetih leta 2015. Prostorska ločljivost LCM2015 je enaka kot pri LCM2007, ima pa zadnja različica v primerjavi s predhodno dva razreda pokrovnosti manj, torej 21. Iz klasifikacije LCM2007 so izločili kategoriji visokogorske travinje in skalovje, obe zaradi težav pri razvrščanju $\mathrm{z}$ avtomatsko klasifikacijo in pomanjkljivih dodatnih virov za jasno razmejevanje razredov (Land Cover Map ... 2017; Land Cover Map ... 2018).

\subsection{Sintezna predstavitev značilnosti rabe in pokrovnosti za analizirane države.}

Vse zbrane podatke analiziranih držav smo za lažjo medsebojno primerjavo združili in predstavili v preglednici 2 . V prvem stolpcu so navedene značilnosti (kazalniki) po katerih smo primerjali vzpostavljene modele rabe in pokrovnosti, $\mathrm{v}$ ostalih stolpcih pa izluščeni podatki za vsako analizirano državo.

\subsection{Mednarodni projekt in aktivnosti}

Pobuda EAGLE (European Action Group for Land Monitoring in Europe) je sprva delovala na prostovoljni ravni, od leta 2014 pa jo financira Evropska agencija za okolje (EEA) ter združuje strokovnjake iz Avstrije, Češke, Finske, Nemčije, Madžarske, Nizozemske, Norveške, Portugalske, Španije, Švice in Velike Britanije. Njeno delovanje je usmerjeno v izboljšanje prikaza pokrovnosti in rabe zemljišč ter ugotavljanje sprememb v časovnih presekih, predvsem pa v vzpostavitev sistema, ki bo razločeval med rabo in pokrovnostjo ter omogočal popolne informacije o obeh podatkovnih slojih. Veliko napora je vloženega v vzpostavitev podatkovnega modela ter pomenskega povezovanja med vrstami rab in pokrovnosti za prehode iz različnih nacionalnih klasifikacij v enotni sistem na evropski ravni (General ... 2016).

V pobudi EAGLE so predlagali, da se v objektno orientiranem podatkovnem modelu (predstavljenem z UML - Unified Modeling Language) vsaki površinski enoti (land cover unit) pripiše raba, pokrovnost ter druge značilke. Tako lahko površinske enote pomensko povezujemo v odvisnosti od potreb. Kot vir podatkov so priporočili uporabo satelitskih posnetkov Sentinel-2 v povezavi z drugimi podatkovnimi bazami (Arnold in sodelavci 2014; EAGLE ... 2014).

Aktivnosti EAGLE so bile opažene in vključene tudi v projekt HELM (Harmonised European Land Monitoring), ki je v obdobju 2011-2013 potekal v okviru 7. Okvirnega programa in združeval praktično vse članice Evropske unije. Namen projekta HELM je bil ustvariti okolje za izmenjavo mnenj in dobrih praks za vzpostavitev in izboljšanje evropskega sistema spremljanja stanja prostora, pri čemer bi uporabili obstoječe nacionalne podatkovne baze (HELM ... 2014; 2016). 
Preglednica 2: Primerjalna analiza modelov pokrovnosti in rabe v izbranih državah.

\begin{tabular}{|c|c|c|c|c|}
\hline značilnosti & Avstrija & Nemčija & Nizozemska & Velika Britanija \\
\hline poimenovanje & $\begin{array}{l}\text { LISA } \\
\text { Land information } \\
\text { System Austria }\end{array}$ & $\begin{array}{l}\text { DLM-DE } \\
\text { Digitales } \\
\text { Landbedeckunsgmodell } \\
\text { für Deutschland }\end{array}$ & $\begin{array}{l}\text { LGN7 } \\
\text { Landelijk } \\
\text { Grondgebruiksbestand } \\
\text { Nederland }\end{array}$ & $\begin{array}{l}\text { LCM2015 } \\
\text { Land Cover Map }\end{array}$ \\
\hline prva različica & l & 2006 & 1986 & 1990 \\
\hline zadnja različica & 2015 & 2012 & 2013 & 2017 \\
\hline klasifikacijski model & objektno orientiran & objektno orientiran & objektno orientiran & objektno orientiran \\
\hline $\begin{array}{l}\text { razmejevanje med } \\
\text { pokrovnostjo in rabo }\end{array}$ & $\mathrm{DA}$ & $\mathrm{DA}$ & $\mathrm{DA}$ & $\mathrm{NE}$ \\
\hline $\begin{array}{l}\text { število razredov } \\
\text { pokrovnosti }\end{array}$ & 13 & 37 & 39 & 21 \\
\hline število razredov rab & 26 & 17 & 32 & I \\
\hline število značilk & 72 & 1 & 1 & 10 \\
\hline viri podatkov & $\begin{array}{l}\text { - ortofoto posnetki, } \\
\text { - lasersko skeniranje, } \\
\text { - produkti } \\
\text { Copernicus, } \\
\text { Pléiades, } \\
\text { - Sentinel } 1,2 \text {, } \\
\text { - vsi razpoložljivi } \\
\text { nacionalni } \\
\text { prostorski podatki }\end{array}$ & $\begin{array}{l}\text { - } \text { produkti } \\
\text { - Copernicus, } \\
\text { - RapidEye, } \\
\text { - IMAGE, } \\
\text { - SPOT, } \\
\text { - ortofoto posnetki, } \\
\text { - digitalna } \\
\text { topografska karta } \\
\text { (DTK), } \\
\text { - DMC (Disaster } \\
\text { Monitoring } \\
\text { Constellation), }\end{array}$ & $\begin{array}{l}\text { - } \text { topografska karta } \\
\text { (Top10NL), } \\
\text { - zemljiški } \\
\text { informacijski } \\
\text { sistem (LPIS), } \\
\text { - digitalne karte } \\
\text { rabe (BBG), } \\
\text { - osnovne karte } \\
\text { naravnih območij } \\
\text { (BKN), } \\
\text { - LGN6 } \\
\text { - satelitski posnetki } \\
\text { (Landsat, IRS-P6 } \\
\text { LISS-IV, LISS-III, } \\
\text { AWiFS, } \\
\text { - ortofoto posnetki }\end{array}$ & 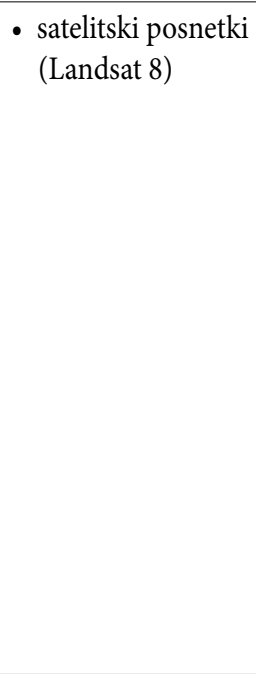 \\
\hline $\begin{array}{l}\text { najmanjša enota } \\
\text { kartiranja }\end{array}$ & $25 \mathrm{~m}^{2}, 50 \mathrm{~m}^{2}$ & $100 \mathrm{~m}^{2}$ & $25 \mathrm{~m}^{2}$ & $50 \mathrm{~m}^{2}$ \\
\hline pristojnost & $\begin{array}{l}\text { raziskovalni projekt, } \\
\text { koordinator GeoVille } \\
\mathrm{GmbH}\end{array}$ & $\begin{array}{l}\text { Wageningen University } \\
\text { and Research Center }\end{array}$ & $\begin{array}{l}\text { Bundesamt für } \\
\text { Kartographie und } \\
\text { Geodäsie (BKG) }\end{array}$ & $\begin{array}{l}\text { Centre for Ecology \& } \\
\text { Hydrology }\end{array}$ \\
\hline dostopnost podatkov & $\begin{array}{l}\text { Land Information ... } \\
2104\end{array}$ & $\begin{array}{l}\text { Digitales ... 2016; } \\
2017\end{array}$ & Ordering ... 2018 & $\begin{array}{l}\text { Land Cover Map ... } \\
\text { 2016, } \\
\text { Land Cover Map ... } \\
2018\end{array}$ \\
\hline
\end{tabular}


V želji po uskladitvi podatkov o pokrovnosti in rabi tal v vseh 27 članicah Evropske unije je pomemben tudi projekt LUCAS (Land Use and Cover Area Frame Survey), ki je bil izveden pod okriljem Eurostata. Metoda zbiranja podatkov je precej groba, saj temelji na določitvi rabe in pokrovnosti za točke, ki so medsebojno oddaljene $2 \mathrm{~km}$ (Land Cover/Use Statistics ... 2018). V prvi fazi so za 1,1 milijona različnih točk v Evropi s pomočjo fotointerpretacije določili razred pokrovnosti ( 25 razredov). V drugi fazi so za približno 270.000 točk zbrali natančnejše podatke na terenu (predvsem kakovost prsti) ter točke uvrstili v 33 razredov rab. Podatki so namenjeni zgolj za statistične obdelave na ravni NUTS 2 regij Evropske unije z namenom spremljanja uresničevanja evropskih politik in direktiv (LUCAS 2017a; 2017b).

\section{Razprava}

Kot ugotavljajo Hovenbitzer in sodelavci $(2014,257)$, so podatki, ki jih zagotavljata Evropska agencija za okolje (CLC, Urban Atlas) in Eurostat (LUCAS), dobro zasnovani s široko možnostjo uporabe na evropski ravni, vendar to pogosto ne odgovarja potrebam na državni in lokalni ravni. Podatki so pregrobi, najmanjša enota kartiranja je prevelika. Banko in sodelavci (2014) poudarjajo, da zahtevajo uporabniki podrobnejše podatke ter predvsem sprotno spremljanje procesov.

Omejena možnost uporabe podatkov (CLC, Urban Atlas) velja tudi za Slovenijo, kjer prevladujeta razpršena poselitev in drobne prostorske strukture, zato $\mathrm{z}$ velikimi enotami kartiranja ne moremo zaobjeti vseh podrobnosti površja.

Pomemben vzvod za vzpostavitev nacionalnih baz pokrovnosti in rabe, je uporaba že obstoječih (katastrskih, topografskih, LPIS in drugih) podatkov na državni ravni ter izogibanje dodatnemu zbiranju podatkov le za določen namen. Pristop od spodaj navzgor pomeni izkoristek obstoječih podatkovnih baz ter snovanje modelov z upoštevanjem značilnosti in potreb lokalnega okolja. Vendar je ob takem pristopu potreben model usklajevanja za evropske potrebe. Prav te ugotovitve so eno od vodil iniciative EAGLE (EAGLE ... 2014).

Ključno za vzpostavljanje nacionalnih baz pokrovnosti in rabe, je široka dostopnost satelitskih posnetkov visoke ločljivosti ter hiter razvoj metod in tehnik za samodejno objektno klasifikacijo. Prosta dostopnost podatkov Sentinel-1 in Sentinel-2 bo v prihodnje bistveno prispevala k povečanju kakovosti podatkov ter bo povod za nadgradnjo obstoječih baz.

Vse obravnavane države, razen Avstrije (LISA je raziskovalni projekt in še nima operativnih rezultatov), imajo vzpostavljene podatke pokrovnosti na državni ravni. Z izjemo Velike Britanije so v vseh državah prešli na ločeno vodenje podatkov pokrovnosti in rabe. Razmejevanje teh dveh kategorij predvideva tudi LISA (Avstrija), prav tako pa so to priporočila pobude EAGLE. Pomen razmejevanja teh dveh kategorij smo nakazali v poglavju 2.2. Model pokrovnosti in rabe je v vseh državah objektno orientiran, minimalna enota kartiranja je od $25 \mathrm{~m}^{2} \mathrm{v}$ Avstriji do $100 \mathrm{~m}^{2} \mathrm{v}$ Nemčiji. Podatki so na razpolago v vektorski ali rastrski obliki.

Vzpostavitev pokrovnosti in rabe poteka $\mathrm{v}$ vseh obravnavanih državah ob sodelovanju različnih državnih služb, strokovnih in raziskovalnih ustanov. V Nemčiji se je pristojnost s Statističnega urada Nemčije (Destatis) prenesla na Državno agencija za kartografijo in geodezijo (Bundesamt für Kartographie und Geodäsie - BKG), kar je odločilno vplivalo na prehod s statističnega gledišča v celostni pristop, zasnovan od spodaj navzgor (Hovenbitzer in sodelavci 2014).

K vzpostavitvi nacionalnih baz pokrovnosti, je veliko prispeval LPIS (Land Parcel Identification System), vzpostavljen v državah Evropske unije za potrebe evropske kmetijske politike, ki zagotavlja podrobne in ažurne podatke za kmetijska zemljišča, ki v večini obravnavanih držav prevladujejo. Na ta način je z veliko natančnostjo in ob metodoloških popravkih že zagotovljeno veliko podatkov za večji del ozemlja države.

Posebej lahko izpostavimo pomen spremljanja stanja prostora in razvoj metodologij za ugotavljanje sprememb. Izvedene so primerjave med različicami podatkov (na Nizozemskem med LGN5 in LGN6; 
v Nemčiji med DLM-DE 2006 in DLM-DE 2009). Tudi v Avstriji je pomemben del projekta LISA predvidena izdelava kart vročih točk (hot spots), z namenom osredotočenega spremljanja prostorskih procesov. Zaznane spremembe so posledica metodoloških napak in dejanskih sprememb v prostoru (Hazau in sodelavci 2011), razumevanje sprememb pa zahteva poznavanje podatkov in široko znanje interpretatorja (Keile in sodelavci 2015).

Posebni napori so vloženi v usklajevanje podatkov za potrebe CORINE Land Cover, kar je opazno predvsem pri projektu LISA in DLM-DE ter v pobudi EAGLE.

Kot smo izpostavili v uvodu, v Sloveniji nimamo baze pokrovnosti in rabe, ki bi zvezno in $\mathrm{z}$ enako natančnostjo pokrivala ozemlje Slovenije. Tako kot ugotavljajo v drugih državah (Avstrija, Nemčija) so podatki CLC le pogojno primerni za analize na državni ravni, za podrobnejše analize pa neuporabni. Evidenca dejanske rabe kmetijskih in gozdnih zemljišč Ministrstva za kmetijstvo, gozdarstvo in prehrano, ki zvezno pokriva območje Slovenije ter se tudi redno vzdržuje, je kombinacija rabe in pokrovnosti. Minimalna enota zajema (od $25 \mathrm{~m}^{2}$ do $1000 \mathrm{~m}^{2}$ ) se razlikuje glede na vrste rabe. Velika pomanjkljivost je neenakomerna podrobnost prikaza, saj poseljeni, vodni in gozdni prostor nimajo podrobnejših razredov. Ta pomanjkljivost je še posebej zaznana $\mathrm{v}$ poseljenem prostoru, kjer poteka največ procesov, ti pa so pomembni za odločevalce v strokovni in upravni sferi.

Obstoječa Evidenca se kljub svojim pomanjkljivostim uporablja v različne namene (Foški 2018), a pogosto zelo nekritično. Prav zaradi njene omejene možnosti uporabe, potekajo aktivnosti za vzpostavitev tudi drugih evidenc za potrebe posameznega resorja oziroma za podrobnejšo določitev vrste rabe. Tako je bil izveden pilotni projekt Evidence dejanske rabe vodnih zemljišč (Mivšek in sodelavci 2012; Barborič in sodelavci 2017), evidence dejanske rabe poseljenega prostora (Masovni ... 2017, Uredba ... 2018) ter določitve dejanske rabe javne cestne in železniške infrastrukture (Predlog ... 2017). Vzpostavil jih je vsak resor v okviru svojih pristojnosti in za lastne potrebe. S predlogom Uredbe o dejanski rabi zemljišč (2018) so zaznane težnje po vzpostavitvi skupnega sloja dejanske rabe na podlagi pridobljenih podatkov iz evidenc različnih resorjev. Smiselno bi bilo, da bi bile aktivnosti povezane ter usmerjene v skupni cilj vzpostavitve podatkov o dejanski rabi in pokrovnosti ter v izgradnjo modela, ki bo vzdržen in uporaben za raznolike potrebe.

Tako v tujini kot v Sloveniji se postopno prehaja k avtomatiziranemu zajemu in vzdrževanju podatkov z metodami avtomatske klasifikacije iz podatkov daljinskega zaznavanja, kar bi pohitrilo ter racionaliziralo delo in stroške (Mesner 2016; Jenko 2017).

Podatki o rabi in pokrovnosti so pomembni za javni in zasebni sektor. $\mathrm{V}$ javnem sektorju jih potrebujemo predvsem za sprejem političnih in strokovnih odločitev, učinkovito upravljanje in administracijo ter za osebne potrebe državljanov. Tovrstne podatke potrebujemo na vseh ravneh in za vse resorje. Brez kakovostnih podatkov odločevalski in upravljavski proces ne moreta delovati. V zameno trenutnemu sistemu, ko vzpostavljamo baze za en in določen namen, bi bil potreben razmislek o vzpostavitvi večuporabniškega podatkovnega modela, ki ne služi le enemu uporabniku. Temu so se najbolj približali v Avstriji s projektom LISA, ki pa se še ne izvaja na ravni celotne države.

\section{Sklep}

Na podlagi izvedenega pregleda ugotavljamo, da bi za potrebe različnih resorjev morali pristopiti $\mathrm{k}$ vzpostavitvi ločenega sloja pokrovnosti in rabe tudi v Sloveniji. Zaznane so aktivnosti za vzpostavitev evidence dejanske rabe pod okriljem različnih resorjev, vendar potekajo nepovezano in v okviru potreb resorjev. Smiselno bi bilo aktivnosti povezati in usmeriti v skupni cilj vzpostavitve podatkov o dejanski rabi in pokrovnosti in v izgradnjo modela, ki bo vzdržen in uporaben za raznolike potrebe ter na različnih ravneh (država, Evropska unija). Pri vzpostavitvi državnega sloja rabe, ki bi z enako podrobnostjo opredeljeval celotno območje Slovenije, bi se lahko opirali na znanje in izkušnje drugih držav. Predvsem projekt LISA je zelo široko zastavljen, njegovo prednost pa vidimo tudi v zasnovi metodo- 
logije za učinkovito spremljanje sprememb v prostoru (vroče točke). Pomembno gonilo je vedno večja dostopnost kakovostnih satelitskih podatkov ter razvoj metod avtomatiziranega zajema in vzdrževanja podatkov, ki pohitrijo in racionalizirajo delo. Kot kažejo izsledki drugih držav, lahko s takimi podatki spremljamo procese v prostoru, ter nudimo podporo prostorskemu, ekonomskemu in socialnemu načrtovanju in odločanju.

Zahvala: Raziskava je bila opravljena v okviru Ciljno raziskovalnega projekta V2-1620, ki sta ga sofinancirala Javna agencija za raziskovalno dejavnost Republike Slovenije in Ministrstvo za kmetijstvo gozdarstvo in prehrano iz državnega proračuna.

\section{Viri in literatura}

Anderson J. R, Hardy E. E., Roach J. T., Witmer R. E. 1976: A Land Use and Land Cover Classification System for Use with Remote Sensor Data. Geological Survey Professional Paper 964. Washington. Antrop, M. 2005: Why landscapes of the past are important for the future. Landscape and Urban Planning 70, 1-2. DOI: https:// doi.org/10.1016/j.landurbplan.2003.10.002

Arnold, S., Kosztra, B., Banko, G., Smith, G., Hazeu, G., Bock, M., Valcarcel Sanz, N. 2014: The EAGLE Concept - A Vision of a Future European Land Monitoring Framework. Medmrežje: http://sia.eionet.europa.eu/EAGLE/Outcomes/EARSeL-Symposium-2013_10_2_EAGLE-concept_ Arnold-et-al.pdf (10.5.2017).

Banko, G., Mansberger, R., Gallaun, H., Grillmayer, R., Pruller, R., Riedl, M., Stemberger, W., Steinnocher, K., Walli, A. 2014: Land Information System Austria (LISA). Land Use and Land Cover Mapping in Europe. New York. DOI: https://doi.org/10.1007/978-94-007-7969-3_15

Barborič, B., Triglav Čekada, M., Bric, V., Kete, P., Dežman Kete, V. 2017: Nove podatkovne podlage za boljše upravljanje z vodami. Trajnostni razvoj mest in naravne nesreče, Naravne nesreče 4. Ljubljana.

Ben-Asher, Z. (ur.) 2013: HELM - Harmonised European Land Monitoring: Findings and Recommendations of the HELM Project. Tel-Aviv. Medmrežje: http://www.fp7helm.eu/fileadmin/site/fp7helm/ HELM_Book_2nd_Edition.pdf (20.6.2017).

CadasterENV - Overview (LISA). Medmrežje: https://www.landinformationsystem.at/\#/cadaster-env/ overview (15.1.2017).

CadasterENV - Products (LISA). Medmrežje: https://www.landinformationsystem.at/\#/cadaster-envaustria/products (24.1.2018).

Comber, A. J. 2008: Land use or land cover? Journal of Land Use Science 3-4. DOI: https://doi.org/ $10.1080 / 17474230802465140$

Copernicus Land Monitoring Service - Local Component: Urban Atlas, 2017. Medmrežje: https://land.copernicus.eu/local/urban-atlas (24.5.2018).

De Witt, A. J. W. 2003: Land use mapping and monitoring in the Netherlands using remote sensing data. Geoscience and Remote Sensing Symposium. Toulouse. DOI: https://doi.org/10.1109/ IGARSS.2003.1294527

Development of the Austrian Land Information System (LISA). Medmrežje: http://www.landinformationsystem.at/en-us/lisa/overview.aspx (10.9.2018).

Digitales Landbedecklungsmodell für Deutschland (LBM-DE). Medmrežje: https://www.bkg.bund.de/DE/ Produkte-und-Services/Shop-und-Downloads/Digitale-Geodaten/Landschaftsmodelle/Deutschland/ deutschland.html (20.6.2017).

Digitales Landbedeckungsmodell für Deutchland DLM-DE2009, 2012. Medmrežje: http://www.geodatenzentrum.de/docpdf/dlm-de2009.pdf (20.5.2018).

Digitales Landbedeckungsmodell für Deutchland DLM-DE2012, 2016. Medmrežje: http://www.geodatenzentrum.de/docpdf/lbm-de2012.pdf (20.5.2018). 
EAGLE - Eionet Action Group on Land monitoring in Europe. European Environment Agency, 2014. Medmrežje: http://sia.eionet.europa.eu/EAGLE/\#Who_is_EAGLE (14.9.2017).

EEA. European Environmental Agency, 2015. Medmrežje: https://www.eea.europa.eu/themes/ landuse (1.6.2017).

Ellis, E. 2010: Land-use and land-cover change. Encyclopedia of Earth. Medmrežje: http://www.eoearth.org/ view/article/51cbee4f7896bb431f696e7b/ (14.9.2017).

FAO. Food and Agriculture Organisation, 2017. Medmrežje: http://www.fao.org/docrep/003/x0596e/ x0596e01e.htm (7.6.2017).

Foški, M. 2018: The (non)usefulness of the register of existing agricultural and forest land use for monitoring the processes in urban areas. Acta geographica Slovenica 58-1. DOI: https://doi.org/ 10.3986/AGS.1805

General Information on EAGLE: Medmrežje: https://land.copernicus.eu/eagle/general-information (14. 10.2016).

Hazeu G. W. Bregt, A. K., de Wit, A. J. W., Clevers J. G. P. W. 2011: A Dutch multi-date land use database: Identification of real and methodological changes. International Journal of Applied Earth Observation and Geoinformation 13-4. DOI: https://doi.org/10.1016/j.jag.2011.04.004

Hazeu, G. W. 2006: Land use mapping and monitoring in the Netherlands (LGN5). Proceedings of the $2^{\text {nd }}$ Workshop of the EARSeL SIG on Land Use and Land Cover. Bonn.

Hazeu, G. W. 2014: Operational land cover and land use mapping in the Netherlands. Land Use and Land Cover Mapping in Europe. DOI: https://doi.org/10.1007/978-94-007-7969-3_18

HELM - Harmonised European Land Monitoring, 2014: Medmrežje: http://www.fp7helm.eu/fileadmin/ site/fp7helm/HELM_Book_2nd_Edition.pdf (10.10.2017).

HELM - Harmonised European Land Monitoring. Medmrežje: http://www.umweltbundesamt.at/ en_helm/ (14.10.2016).

Hovenbitzer, M., Emig, F., Wende, C., Arnold, S., Bock, M., Feigenspan, S. 2014: Digital land cover model for Germany - DLM-DE. Land Use and Land Cover Mapping in Europe. DOI: https://doi.org/ 10.1007/978-94-007-7969-3_16

INSPIRE 2013a: D2.8.II.2 Data specification on land cover - technical guidelines, version 3.0. European Commission. Medmrežje: http://inspire.ec.europa.eu/index.cfm/pageid/2 (10.9.2017).

INSPIRE 2013b: D2.8.III.4 Data specification on land use - technical guidelines, version 3.0. European Commission. Medmrežje: http://inspire.ec.europa.eu/index.cfm/pageid/2 (10.9.2017).

INSPIRE 2014: Infrastructure for spatial information in the European Community. European Commission. Medmrežje: http://inspire.ec.europa.eu/index.cfm/pageid/2 (10.9. 2017).

Jenko D. 2017: Objektna klasifikacija podatkov ortofota in laserskega skeniranja za aplikacijo v prostorskem načrtovanju. Magistrsko delo, Fakulteta za gradbeništvo in geodezijo Univerze v Ljubljani. Ljubljana.

Keil, M., Esch, T., Divanis, A., Marconcini, M., Metz, A., Ottinger, M., Voinov, S., Wiesner, M., Wurm, M., Zeidler, J. 2015: Updating the Land Use and Land Cover Database CLC for the Year 2012 - »Backdating" of DLM-DE from the Reference Year 2009 to the Year 2006: Medmrežje: http://www.umweltbundesamt.de/publikationen/updating-the-land-use-land-cover-database-clc-for (20.1.2018).

Kokalj Ž., Oštir K. 2005:Ugotavljanje pokrovnosti iz satelitskih posnetkov in vrednotenje pokrajinskoekoloških tipov Slovenije. Geografski obzornik 52-4.

Krevs, M. 2004: Spreminjanje urbane rabe tal v Ljubljani. Dela 22-5. DOI: https://doi.org/10.4312/ DELA.22.5.55-65

Land Cover Map 2007 (25m raster) v1.2, 2016. Medmrežje: https://data.gov.uk/dataset/land-cover-map2007-25m-raster-gb-v1-2 (20.6.2017).

Land Cover Map 2015 - Dataset documentation, 2017. Medmrežje: https://www.ceh.ac.uk/sites/default/ files/LCM2015_Dataset_Documentation_22May2017.pdf (22.1.2017). 
Land Cover Map 2015, 2018. Medmrežje: https://data.gov.uk/dataset/land-cover-map-2015-vector-gb (24. 5. 2018).

Land Cover/Use Statistics (LUCAS) - Methodology. Medmrežje: http://ec.europa.eu/eurostat/web/lucas/ methodology (24.1.2018).

Land Cover Map 2007 - Dataset Documentation, 2011. Medmrežje: https://www.ceh.ac.uk/sites/default/ files/LCM2007\%20dataset\%20documentation.pdf (7.7.2017).

Land Information System Austria (LISA), 2014. Medmrežje: http://www.landinformationsystem.at/ (20.10.2017).

LGN7. Medmrežje: https://www.wur.nl/en/Expertise-Services/Research-Institutes/EnvironmentalResearch/Facilities-Products/Land-use-database-of-the-Netherlands/Different-Versions-of-Databases/ LGN7.htm (16.1.2017).

LISA mapping services - General Overview. Medmrežje: https://www.landinformationsystem.at/\#/mapping-services/general-overview (15.1.2017).

Lisec, A., Pišek, J., Drobne, S. 2013: Suitability analysis of land use records of agricultural and forest land for detecting land use change on the case of the Pomurska statistical region. Acta geographica Slovenica 53-1. DOI: https://doi.org/10.3986/AGS53104

LUCAS 2017a: Classification of land cover. Medmrežje: http://ec.europa.eu/eurostat/statistics-explained/ index.php/File:LUCAS_\%E2\%80\%94_classification_of_land_cover.png (20.6.2017).

LUCAS 2017b: Land use and land cover survey. Medmrežje: http://ec.europa.eu/eurostat/statistics-explained/index.php/LUCAS_-_Land_use_and_land_cover_survey (20.6.2017).

Manakos, I., Braun, M. (ur.) 2014: Land Use and Land Cover Mapping in Europe: Practice and Trends. New York. DOI: https://doi.org/10.1007/978-94-007-7969-3

Manual of Concepts on Land Cover and Land Use Information Systems. European Commission. Luxembourg, 2001. Medmrežje: http://ec.europa.eu/eurostat/ramon/statmanuals/files/KS-34-00-407-_-I-EN.pdf (7.6.2017).

Masovni zajem poseljenih zemljišč in dejanske rabe poseljenih zemljišč. Geodetska uprava Republike Slovenije. Ljubljana, 2017. Medmrežje: http://www.gu.gov.si/fileadmin/gu.gov.si/pageuploads/ JVN_2017/odprtni_postopek/28._Masovni_zajem_poseljenih_zemljisc_in_dejanske_rabe_poseljenih_ zemljisc/Tehnicna_dokumentacija_MZ.pdf (10.1.2018).

Medmrežje 1: http://lucc.zrc-sazu.si/Home.aspx (23.5.2018).

Medmrežje 2: https://land.copernicus.eu/local/urban-atlas/change-2006-2009/view (24.1.2018).

Medmrežje 3: https://www.landinformationsystem.at/\#/project-partners (26. 5. 2018).

Mesner, N. 2016: Analiza možnosti uporabe samodejne klasifikacije podobe za vzdrževanje prostorskih podatkovnih zbirk. Magistrsko delo, Fakulteta za gradbeništvo in geodezijo Univerze v Ljubljani. Ljubljana.

Metodologija vodenja in vzdrževanja dejanske rabe zemljišč v zemljiškem katastru. Geodetska uprava Republike Slovenije. Ljubljana, 2018. Medmrežje: http://www.gu.gov.si/fileadmin/gu.gov.si/ pageuploads/zakonodaja/ZEN_am/metodologija_dejanska_raba_GU.pdf (24.5.2018).

Mivšek, E., Pegan Žvokelj, B., Kete, P., Globokar, T. 2012: Dejanska raba vodnih zemljišč in zemljiški kataster. Geodetski vestnik 56-4. DOI: 10.15292/geodetski-vestnik.2012.04.663-673

Okršlar, G. 2015: Predlog kategorij dejanske rabe prostora s primerjavo mednarodnih klasifikacij. Magistrsko delo, Fakulteta za gradbeništvo in geodezijo Univerze v Ljubljani. Ljubljana.

Ordering the LGN Database. Medmrežje: https://www.wur.nl/en/Research-Results/ResearchInstitutes/Environmental-Research/Facilities-Products/Land-use-database-of-the-Netherlands/Orderi ng-the-LGN-database.htm (24.1.2018).

Plieninger, T., Draux, H., Fagerholm, N., Bieling, C., Bürgi, M., Kizos, T., Kuemmerle, T., Primdahl J., Verburg, P. H. 2016: The driving forces of landscape change in Europe: a systematic review of the evidence. Land Use Policy 57. DOI: https://doi.org/10.1016/j.landusepol.2016.04.040

Pogačnik A. 1992: Urejanje prostora in varstvo okolja. Ljubljana. 
Pravilnik o evidenci dejanske rabe kmetijskih in gozdnih zemljišč. Uradni list Republike Slovenije122/2008, $4 / 2010$ in 110/2010. Ljubljana.

Predlog Zakona o evidentiranju dejanske rabe zemljišč javne cestne in železniške infrastrukture - prva obravnava. Ministrstvo za infrastrukturo. Ljubljana, 2017.

Skumavec, D., Šabić, D. 2005: Pokrovnost tal v Sloveniji 1993-2001. Rezultati raziskovanj. Statistični urad Republike Slovenije. Ljubljana. Medmrežje: http://www.stat.si/doc/pub/rr-815-05.pdf (14. 2. 2017).

Smith, G. M. 2014: Land use \& land cover mapping in Europe: examples from UK. Land Use and Land Cover Mapping in Europe. New York. DOI: https://doi.org/10.1007/978-94-007-7969-3_17

SURS 2007: Površina ozemlja in pokrovnost tal, določena planimetrično, Slovenija, 2005. Medmrežje: http://www.stat.si/novica_prikazi.aspx?id=977 (14.2.2017).

SURS 2017. Medmrežje: http://www.stat.si/StatWeb/File/DocSysFile/8158 (1.7. 2017).

Tavares, A. O., Pato, R. L., Magalhaes, M. C. 2012: Spatial and temporal land use change and occupation over the last half century in a peri-urban area. Applied Geography 34. DOI: https://doi.org/10.1016/ j.apgeog.2012.01.009

The Land Use Database of the Netherlands (LGN database). Wageningen UR, 2015. Medmrežje: http://www.wageningenur.nl/en/Expertise-Services/Research-Institutes/alterra/Facilities-Products/ Land-use-database-of-the-Netherlands.htm (3.1.2015).

Uredba o dejanski rabi zemljišč-predlog za obravnavo. Ministrstvo za okolje in prostor. Ljubljana, 2018. Medmrežje: http://www.gu.gov.si/si/zakonodaja_in_dokumenti/materialni_predpisi/zen0/ (24.5.2018).

Van der Sluis, T., Pedroli, B., Kristensen, S. B. P., Lavinia Cosor, G., Pavlis, E. 2015: Changing land use intensity in Europe - Recent processes in selected case studies. Land Use Policy 57. DOI: https://doi.org/ 10.1016/j.landusepol.2014.12.005

What is the LGN database? Medmrežje: https:/www.wur.nl/en/Research-Results/ResearchInstitutes/Environmental-Research/Facilities-Products/Land-use-database-of-the-Netherlands/Whatis-the-LGN-database.htm (22.6.2017).

Zakon o urejanju prostora. Uradni list Republike Slovenije 61/2017. Ljubljana.

\section{Summary: Comparative analysis of land cover and land use models in selected countries}

(translated by Mojca Vilfan)

Land cover and land use are often correlated characteristics of the Earth's surface while, in fact, they represent two different pieces of spatial information. The relationships between the categories of land cover and land use (Figures 1 and 2) can have a ratio of $1: 1,1: n$, or $n: 1$. Because of this land cover data cannot be unambiguously transformed into land use, and as a consequence the number of land use and land cover categories varies, as also confirmed in the analysis by Okršlar (2015). Land use can be deduced from land cover, but the information about the intensity thereof in a certain area is lacking. Changes in activities (e.g. from housing to commercial) and changes in land use intensity are not reflected in land cover, unless the changes in intensity are significant (Van der Sluis et al. 2015). This is why it is essential to distinguish between land use and land cover.

Statistical Land Cover GIS (Statistical Office of the Republic of Slovenia) data are no longer kept in Slovenia; the only record covering the entire state territory continuously, where land cover and land use are used interchangeably, is the Land use database of agricultural and forest land kept by the ministry responsible for agriculture, while its deficiencies to be used outside its dedicated purpose have been underlined by several authors (e.g., Krevs 2004; Lisec, Pišek and Drobne 2013; Foški 2018). The minimum capture unit (from $25 \mathrm{~m}^{2}$ to $1000 \mathrm{~m}^{2}$ ) varies according to the type of land use. A great disadvantage is the uneven detail of representation, as built-up, water, and forest areas lack detailed land 
use/cover classes. This deficiency has been particularly identified in built-up areas, where the most processes significant for decision-makers in professional and administrative spheres take place.

At the European level, CORINE Land Cover (EEA) data are available at 5-year production periodicity, while Urban Atlas data are updated every three years (so far in 2012 and 2015) and particularly provide information on land use for urban areas. For Slovenia, data for Osrednjeslovenska (Central Slovenia) and Podravska (in the north-east) statistical regions are available (Medmrežje 2). According to Banko et al. (2014) and Hovenbitzer et al. (2014, 257), the mapping units are too large (25 ha for open space and 0.25 ha for built-up areas), and the data are too generalised, as they fail to cover the entire territory evenly, making them unsuitable for decision-making and governance processes. Better information is necessary, allowing for monitoring and keeping up with the processes at the local level (Banko et al. 2014). These conclusions are valid for Slovenia as well. As Slovenia has a very diverse and fragmented vegetation cover and is characterised by dispersed settlement, large mapping units fail to reflect the conditions and changes in space, particularly not at the local level.

Therefore, this paper provides an overview of land cover and land use models in Austria, Germany, The Netherlands, and Great Britain (summaries are provided in Table 2) and the activities under the European projects EAGLE and HELM. Both projects were concerned with the establishment of national databases on land use and land cover and with suitable environments for harmonisation of the data for EU needs (EAGLE ... 2014; HELM 2015).

Except for Austria (with Land Information System Austria (LISA) being a research project, still lacking operating results), all the countries considered here have put in place databases on land cover at the national level. Except for Great Britain, data on land cover and land use are kept separately in all other countries. LISA also differentiates between these two categories; this is also one of the recommendations of the EAGLE initiative. The significance of distinguishing between the two categories was indicated in Chapter 2.2. The land cover and land use models in all these countries are object-oriented, and the minimum mapping unit is between $25 \mathrm{~m}^{2}$ in Austria up to $100 \mathrm{~m}^{2}$ in Germany. The data are available in vector and raster format.

Establishment of land cover and land use databases is underway in all countries in collaboration of various governmental offices, professional, and research institutions. In Germany the jurisdiction was transferred from the Federal Statistical Office (Destatis) to the Federal Agency for Cartography and Geodesy (BKG), which played a determining role in the transition from the statistical viewpoint to an integrated, bottom-up approach (Hovenbitzer et al. 2014).

The Land Parcel Identification System (LPIS) greatly contributed to the setting-up of national land cover databases, allowing for detailed and up-to-date data on agricultural land, which prevail in most of the countries analysed. Along with methodological revisions, the high level of accuracy provides good data coverage in most of the national territory.

The large availability of high-resolution satellite imagery and the rapid development of methods and techniques for automated object-based classification are essential in establishing national land cover and land use databases. Free and open access to Sentinel-1 and Sentinel-2 data will in the future significantly increase data quality and will result in upgrading of the existing databases.

The significance of monitoring of land use changes and development of methodologies for identifying the changes are particularly underlined. Comparisons between various data versions are made (in The Netherlands between LGN5 and LGN6; in Germany between DLM-DE 2006 and DLM-DE 2009). In Austria, an important part of LISA was the production of hot spots maps to implement focused monitoring of spatial processes. The changes detected in space are the consequence of both methodological errors and actual changes in space (Hazau et al. 2011), while the understanding of the changes requires the interpreter's familiarity with the data and general knowledge (Keil et al. 2015).

Special efforts have been made to coordinate the data for the needs of CORINE Land Cover, which is particularly evident in the LISA project, DLM-DE, and the EAGLE initiative. 
As underlined in the Introduction, Slovenia lacks appropriate data on land cover and land use, so the existing Land use database of agricultural and forest land is often used for unsuitable purposes (Foški 2018). Furthermore, activities concerned with establishing databases on land use of waterside land (Mivšek et al. 2012; Barborič et al. 2017), land use of built-up areas (Masovni ... 2017), and identification of land use of public road and railway infrastructure (Predlog ... 2017) have been identified. Trends for acquiring and maintaining data using methods of automated classification of remote sensing data have been identified (Mesner 2016; Jenko 2017). We hope that the activities are integrated and directed towards a common goal of establishing a database on land use and land cover and building a model that will be sustainable and applicable for various purposes.

The data on land use and land cover are significant both for the public and private sector. In the public sector they are used for making political and professional decisions, effective governance, administration, and for citizens' personal matters. These data are needed at all levels and for all sectors. The decision-making and governance systems cannot function without high-quality data. Contrary to the current system where databases are set up for one specific reason only, it would be necessary to consider the setting-up of a multi-purpose database model, serving several users rather than just one. The Austrian LISA project came closest to this; however, the project is still under development and is not yet implemented across the entire country. 